\title{
Discussion on Cultural Strategy and World's Pluralistic Music Education
}

\author{
Yifei Shen \\ Jiujiang Primary School, Jiujiang 332000, Jiangxi, China \\ Email: 15279103007@163.com
}

\begin{abstract}
Culture is characterized by diversity. In the cultural strategy, the development of culture must be restricted by certain factors, and the reason for this restriction is that the development of culture must conform to the development trend of society. Therefore, the current music education should be implemented from the perspectives of multiculture and cultural strategies to reflect the value and significance of music education.

Keywords: cultural strategy, world's pluralistic music education, positive influence, ways of implementation
\end{abstract}

\section{Introduction}

As an art form that combines natural sciences with humanities, music is an important part of culture in the superstructure. The process from music creation, performance to appreciation is all permeated with the connotation and spirit of culture. From the perspective of various forms and processes of music practice, music education is like a "narrative thread" that organically intersperses the various practices and becomes the basis of various music practices. No matter from the vertical perspective of history, or from the horizontal cultural presentation of regions and nationalities, music culture shows the characteristics of diversity. Coupled with the development of economic, social and other objective factors and the in-depth exchanges between countries around the world, how to practice the globalization and diversification of music education from the perspective of cultural strategies has become an important proposition in the field of music education. Therefore, it is necessary for us to discuss from the perspective of the relationship between cultural strategies and the world's pluralistic music education, in order to find a practical and feasible education model that is conducive to the full development of music art.

\section{The definition and connotation of cultural strategy}

"Cultural strategy" is a compound term, which is a combination of the two concepts of "culture" and "strategy". First of all, from the perspective of the interpretation of "culture", the so-called "Wen" refers to the spiritual carrier that is conducive to the development of human society and the progress of civilization, specifically literature, art, etc.; "Hua" has educational connotations. Therefore, another expression of culture is "use reasonable methods to influence others" ${ }^{[1]}$. Secondly, from the perspective of "strategy", culture can be interpreted as "a plan to achieve goals" and "a policy of action based on the development of the situation." Combining the concepts of "culture" and "strategy" can be called "policies concerning cultural development and specific ways to achieve cultural development based on the characteristics of contemporary and future social development". Therefore, the connotation of the word "cultural strategy" mainly embodies the following three characteristics.

First, since different regions and nations in the world have formed cultures with independent characteristics in the process of creating history, from a macro perspective, culture has the characteristics of diversity. In the cultural strategy, the development of culture must be restricted by certain factors, because the development of culture must conform to the development trend of society. Second, it is necessary to consider the existence of multiple elements in the formulation of cultural strategies, so cultural strategies are not blind in terms of specific policy directions and implementation methods. From the perspective of culture and sociology, culture is a broad macro concept, which "covers all aspects and elements of the economic foundation and superstructure" ${ }^{[2]}$. Therefore, in the formulation and implementation of cultural strategies, it is necessary to recognize the differences of cultures of different regions and nations, and to consider the identity of the common development of cultures. Third, from the perspective of the current world situation, economic globalization and integration provide powerful material conditions for cross-regional and cross-national cultural exchanges. The existence of multiple cultures has become the driving force for mutual exchanges between different regions. These regions seek development in the cultural "seeking common ground while reserving differences" and have formed the diverse pattern of 
today's world. Therefore, in the current era, how to face cultural differences and achieve the goal of peace and development has formed an inseparable relationship, and the formulation and implementation of cultural strategies play an irreplaceable role in it.

\section{The origin of the world's pluralistic music education}

We often say "music is the language of the world" and "music has no boundary". These popular sayings are reasonable. This also shows that in the practice of music education, we can still adopt diversified music education models. But before choosing or innovating a music education model, it is necessary to have a full understanding of the roots of the world's diverse music education. The author believes that the reason why music education presents universality or diversity is mainly based on the following two aspects.

The first is the diversification of music styles. This feature mainly stems from the creative ideas of the music creators and the background of the times. Taking a comprehensive view of the history of Chinese and Western music development, both of them developed in the evolution of style. Take Western music as an example. From the monophonic music of ancient Greece and Rome to the various musical styles presented today, it has gone through different stages of medieval, baroque, classicism, and romanticism. And each stage is in the process of social development changes, which also profoundly affects the creative thinking of music creators. The second is the background of the current social development. Since the Second World War, all countries have been committed to economic and technological development. Under the premise of economic changes, exchanges in various fields between countries have been increasingly strengthened, which has also deepened cultural exchanges. Driven by this background, music education is constantly changing. China's basic music education and higher music education have obvious manifestations. Take basic music education as an example. From the music education model of the former Soviet Union since the founding of the People's Republic of China to the application of various music education systems today, and the practice of music education in the new system in recent years, it can be said that it has experienced several educational changes. These changes highly reflect that the development of basic music education in China cannot be separated from the integration of various music genres. Therefore, to a certain extent, the current background of social development has prompted the emergence of diversified music education in the world.

\section{The positive influence of cultural strategies on the world's pluralistic music education}

Music is essentially an important part of culture, and the formulation and implementation of cultural strategies must also be related to the future development of music art. Music education is the carrier of musical art inheritance and innovation, which to a large extent illustrates the close relationship between it and cultural strategy. The positive influence of cultural strategies on the world's pluralistic music education can be expressed from the following two aspects.

The first is to create a communication platform. The development of music culture lies in promoting and cooperating in communication. The same is true of music education. If you stick to a tradition without understanding and accepting a diversified music culture, then music education will always be in a state of complacency, and it will be difficult to promote exchanges between regions. As early as 2001, UNESCO issued the World Declaration of Cultural Diversity. This declaration clearly put forward the concept of "cultural diversity" ${ }^{[3]}$, expounded the internal mechanism between them from the perspectives of culture and people, culture and creation, and called for more attention to the culture exchanges of various nations and regions in the education process. It is precisely because of this declaration that countries and regions have successively carried out exchanges and cooperation in different fields of culture. The reform of my country's basic music education has also been carried out in an orderly manner. The introduction and application of the world's three major music education systems is the best example of the world's diverse music education.

The second is to develop innovative ideas. Cultural strategies are formulated and implemented according to the current situation and trends of social development. Therefore, scientific, reasonable and cultural strategies that meet the requirements of the times can provide innovative ideas for the development of the world's diverse music education. At present, my country's higher music education focuses on cultivating compound applied talents. This mode of music education and talent training has a very close relationship with the current cultural strategy of our country. Since the 18th National Congress of the Communist Party of China, the "Implementation Plan for Deepening the Reform of the Cultural System" and the "Outline of the National Cultural Development and Reform Plan during the 13th Five-Year Plan Period" have been promulgated and implemented, clarifying the main direction of cultural development in the future. That is, "always adhere to the basic bottom line of the cultural industry development; insist on putting social benefits in the first 
place; establish a system and mechanism that integrates social benefits and economic benefits as the basis of the policy" ${ }^{[4]}$. It is this cultural strategy that has led to innovative ideas in music education and talent training, and the world's diverse music education is in line with the current development of music education in my country.

\section{Ways of implementation of world's pluralistic music education}

According to the background of cultural strategy formulation and the development direction of music teaching, the following three aspects should be considered in the implementation of world's pluralistic music education.

First, break the shackles of stubborn thinking. In the context of the current era when the world's economy and culture are highly integrated, one should adopt a tolerant and accepting attitude towards music from different regions and nations. In particular, there are still factors that are not conducive to the development of music culture, such as racism and unilateralism $^{[5]}$, which have largely hindered the development of multiple music education. This has resulted in the unity of music education models and methods. Therefore, in the process of realizing diversified music education, it is necessary to break the traditional and stubborn thinking, and place the development of music culture at the height of overall social development. The formulation of cultural strategies also needs to lean towards pluralistic music education.

Second, continuously improve the comprehensive level of students in music education. As far as higher music education is concerned, the most obvious problem in teaching at present is that there is still a great lack of comprehensive cultural quality of students. Especially the students' artistic and cultural accomplishments need to be further improved. It is precisely the students' lack of artistic and cultural literacy that make it difficult to carry out diversified music education effectively. This shows that the reform of higher music education is imminent. Therefore, it is necessary to attach great importance to the curriculum, intra-curricular and extra-curricular cooperation, etc., to cultivate compound and applied talents.

Third, music works of multiple styles should be incorporated into basic music education. Basic music education undertakes the important task of cultivating national cultural quality, and is an important carrier for implementing aesthetic education ${ }^{[6]}$. In the selection of teaching materials, works of different musical styles should be selected, especially those with strong humanity and profound ideological connotation. Only in this way can it reflect the diverse characteristics of music education.

\section{Conclusion}

In summary, the world's pluralistic music education is the main trend of current and future music education, and it needs to be highly valued both in basic music education and in higher music education. At the same time, there is an organic connection between the world's diverse music education and corresponding cultural strategies, which shows that the requirements of cultural strategies need to be considered in the implementation of music education. Only in this way can the value and significance of pluralistic music education be reflected.

\section{References}

[1] Xiang Jiuyu, Hou Yuhuan. On the triple meaning of the cultural construction of a community with a shared future for mankind. Jianghuai Tribune. 2019; (5): 136-143.

[2] Lu Shasha. Philosophy of music education with music culture as its core. Journal of Xinghai Conservatory of Music. 2020; (3): 112-120.

[3] Guo Xiaoyan. Analysis of multicultural music education in elementary school music education. Journal of the Chinese Society of Education. 2019; (S02): 85-86.

[4] Du Chengying. The role of multicultural music education in the inheritance of ethnic music culture. Chinese Journal of Education. 2019; (A01): 150-151.

[5] Li Donglan. Diversified music teaching: a special form of cross-cultural communication. Modern Communication (Journal of Communication University of China). 2019; (6): 165-168.

[6] Gao Zhaoxia. Research on the Training Mode of Music Talents in Chinese Universities. Chinese Music. 2019; (1): $151-158$ 